\title{
Building the Language Resource for a Cebuano-Filipino Neural Machine Translation System
}

\author{
Kristine Mae M. Adlaon ${ }^{1,2}$, Nelson Marcos ${ }^{1}$ \\ ${ }^{1}$ College of Computer Studies, De La Salle University, Taft Avenue, Manila, Philippines \\ 2ITE Program, University of the Immaculate Conception, Father Selga St., Davao City, Philippines \\ ${ }^{1}\left\{k\right.$ kistine_adlaon\},\{nelson.marcos\}@dlsu.edu.ph, ${ }^{2}\{k a d l a o n\} @ u i c . e d u . p h$
}

\begin{abstract}
Parallel corpus is a critical resource in machine learning based translation. The task of collecting, extracting, and aligning texts in order to build an acceptable corpus for doing translation is very tedious most especially for low-resource languages. In this paper, we present the efforts made to build a parallel corpus for Cebuano and Filipino from two different domains: biblical texts and the web. For the biblical resource, subword unit translation for verbs and copy-able approach for nouns were applied to correct inconsistencies in translation. This correction mechanism was applied as a preprocessing technique. On the other hand, for Wikipedia being the main web resource, commonly occurring topic segments were extracted from both the source and the target languages. These observed topic segments are unique in 4 different categories. The identification of these topic segments may be used for automatic extraction of sentences. A Recurrent Neural Network was used to implement the translation using OpenNMT sequence modeling tool in TensorFlow. The two different corpora were then evaluated by using them as two separate inputs in the neural network. Results have shown a difference in BLEU score in both corpora.
\end{abstract}

\section{CCS Concept:}

Computing Methodologies $\rightarrow$ Machine Translation

\section{Keywords}

Language resources, neural machine translation, recurrent neural network, Cebuano-Filipino translation, OpenNMT, natural language processing

\section{INTRODUCTION}

Machine translation (MT) in recent years had gained so much interest to many researchers because of its fascinating use in different tasks. Both statistical and neural machine translation approaches are now paving its way towards improving MT in different languages [3],[4],[8]. The Philippines, being a linguistically diverse country could greatly benefit from having an effective MT system as this could help improve in the promotion of educational and cultural development agenda of the country. There have been several efforts already in machine translation for Philippine languages such as that of [5], [7], [9] but no known work had focused on purely Philippine native language alone using the state-of-the-art approaches for MT.

Knowing that both statistical and neural machine translation approaches are highly reliant on the availability of large amounts of data and are known to poorly perform on low-resource settings, this has been then the main motivation of this research work. In this paper, an approach in building the language resource for Cebuano and Filipino (formerly Tagalog) is presented. These two languages are the top most spoken languages in the Philippines $(\mathrm{PH})$. The source of data for this study is parts of the Bible taken from the work of [1], and Philippine geographical information from Wikipedia. We also present in this paper the intensive labor of examining and correcting the source data to come up with a more reliable parallel corpus. We then compare the BLEU scores of the machine translation of the two sources to evaluate whether there is an effect in the quality of the translation given different domain of source using a unidirectional implementation of a recurrent neural network.

\section{RELATED WORK}

To date, efforts in building the language resource for the Philippines are very minimal much more in the curation of parallel corpora for machine translation. The only Cebuano to Filipino (Tagalog) MT effort in the Philippines is that of Fat (2007) who worked on a bilingual machine translation system designed for Tagalog and Cebuano. It exploits structural similarities of the Philippine languages Tagalog and Cebuano, and handles the free word order languages. It translates at the syntactic level only and uses Tagalog to Cebuano dictionary as the dataset. It does not employ morphological analysis in the system. A more recent work used a statistical machine translation (SMT) approach for a bidirectional Filipino to English MT named as the ASEANMTPhil. The system has experimented on different settings producing the BLEU score of 32.71 for Filipino to English and 31.15 for English to Filipino [9].

The approach that was used in this study for inconsistency correction is greatly inspired by the work of [10]. Their work introduced a simpler and more effective approach, making the NMT model capable of open-vocabulary translation by encoding rare and unknown words as sequences of subword units. Several attempts for building a parallel corpus from the Web have already been conducted. The work of Ramesh and Sankaranarayanan [11] have used an end-to-end Siamese bidirectional recurrent neural network to generate parallel sentences from comparable multilingual articles in Wikipedia. Their study has shown that using the harvested dataset improved BLEU scores on both NMT and phrase-based SMT systems for the low-resource language pairs: English- Hindi and English-Tamil.

\section{APPROACH}

In this section, we describe the entire pipeline that this research went through as depicted in Figure 1.

\subsection{Extraction of the Source Data}

The Philippines has very few linguistic resources most especially for parallel corpora. In the past, efforts were made to build the Philippine language resource but were much more focused on Filipino only or English - Filipino for bilingual corpora. To the best of our knowledge at present, no known work for building the 


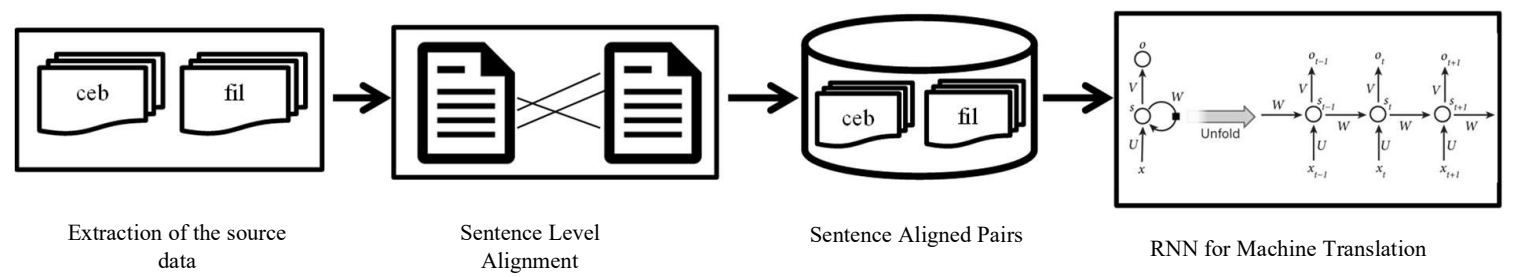

Figure 1: Architecture for the building of the parallel corpus showing four different steps: (a) Extraction of the source data, (b) Sentence Level Alignment, (c) Sentence Aligned Pairs, (d) unidirectional RNN for Machine Translation

parallel corpus for Cebuano-Filipino is currently being done in the Philippines. In this subsection we describe the nature of the source dataset.

Table 1: General information of the dataset

\begin{tabular}{|c|c|c|}
\hline Language & Cebuano & Filipino \\
\hline Family & Austronesian & Austronesian \\
\hline Genus & $\begin{array}{c}\text { Malayo- } \\
\text { Polynesian }\end{array}$ & $\begin{array}{c}\text { Malayo- } \\
\text { Polynesian }\end{array}$ \\
\hline Subgenus & Philippines & Philippines \\
\hline $\begin{array}{c}\text { No. of } \\
\text { Speakers }\end{array}$ & $15,800,000$ & $23,900,000$ \\
\hline $\begin{array}{c}\text { Parts (New or } \\
\text { Old } \\
\text { Testament) }\end{array}$ & Complete & Complete \\
\hline
\end{tabular}

Bible: The dataset was downloaded from the web Bible ${ }^{1}$ that contains a monolingual corpus of different languages created from translations of the Bible which is publicly available. Although it is stated in the source that the corpus's Book, Chapter, and Verse indices are already aligned at a sentence level, inconsistencies in the sentence level translation were still found. Thus, a manual correction (discuss in the next section) was done to address this. The corpus is in XML format. Table 1 shows the general information of the dataset.

Data cleaning and transformation was performed in the dataset. This stage is important in order to transform the data into a format that can be used for processing. We converted the dataset from XML (.xml) file to a text (.txt) file then removed all xml tags and non-printable ASCII characters. We also removed all repetitive sentences that were found mostly in the Cebuano dataset. For the purpose of this research, to check as to what will be the performance of this dataset to translation we only included the Genesis book. After performing the cleaning and transformation of the dataset, a total of 6,510 sentence pairs were generated. Table 2 shows example sentence pairs where Cebuano is the source sentence and Filipino is the target sentence.

Wikipedia: Wikipedia is an online collaborative encyclopedia available in a wide variety of languages. Wikipedia has aligned article pairs that may range from being almost completely parallel to containing almost no parallel sentences. To extract articles from Wikipedia we used a python library Beautiful Soup 2 . The URL to

\footnotetext{
${ }^{1}$ http://christos-c.com/bible/

${ }^{2}$ https://www.crummy.com/software/BeautifulSoup/bs4/doc/
}

be used for pulling data is unique per language following the format shown in Figure 2.

Table 2: Cebuano - Filipino Sentence Pairs from the Bible

\begin{tabular}{|l|l|}
\hline \multicolumn{1}{|c|}{ Cebuano } & \multicolumn{1}{c|}{ Tagalog } \\
\hline $\begin{array}{l}\text { Ug mitubag si jose kang } \\
\text { faraon : ang damgo ni } \\
\text { faraon usa lamang : ang dios } \\
\text { nagpahayag kang faraon sa } \\
\text { haduol na niyang } \\
\text { pagabuhaton . }\end{array}$ & $\begin{array}{l}\text { At sinabi ni jose kay } \\
\text { faraon, ang panaginip ni } \\
\text { faraon ay iisa; ang } \\
\text { gagawin ng dios ay } \\
\text { ipinahayag kay faraon : }\end{array}$ \\
\hline $\begin{array}{l}\text { Ang pito ka mga vaca nga } \\
\text { maanindot mao ang pito ka } \\
\text { tuig; ug ang mga uhay nga } \\
\text { maanindot mao ang pito ka } \\
\text { tuig: ang damgo usa } \\
\text { lamang. }\end{array}$ & $\begin{array}{l}\text { Ang pitong bakang } \\
\text { mabubuti ay pitong taon ; } \\
\text { at ang pitong uhay na } \\
\text { mabubuti ay pitong taon ; } \\
\text { ang panaginip ay iisa . }\end{array}$ \\
\hline
\end{tabular}

Language code $c e b$ is used for Cebuano while $t$ is used for Filipino. They both share the same topic as indicated in the wiki_article.

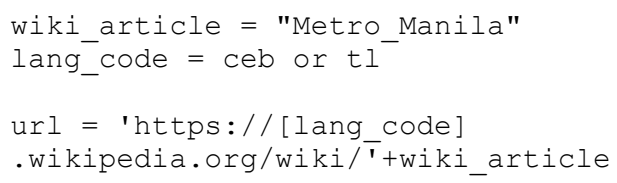

Figure 2: URL format used in scraping

We manually identified categories to be extracted from Wikipedia. These categories were chosen since we have seen that articles in these categories have available data for both languages. The categories are $\mathrm{PH}$ regions, $\mathrm{PH}$ provinces, $\mathrm{PH}$ cities, and PH tourism attractions with 17, 82, 114, and 22 counts respectively. Regions, provinces, and cities are also called administrative divisions of the Philippines, often lumped together as Local Government Unit (LGU). Shown in Table 3 are sample snippets of the extracted data.

To match with the number of sentence pairs extracted from the Bible, we have also extracted a total of 6,510 sentence pairs for Wiki articles. We were able to obtain 1537, 1929, 2044, and 1000 sentences for regions, provinces, cities, and tourism attractions respectively. 


\subsection{Sentence Level Alignment}

In this section, we discuss the strategies that we applied for both the Bible and Wikipedia texts to come up with a sentence aligned parallel corpus. Most of these strategies were applied to address inconsistences seen in the extracted data.

Table 3: Snippet of the texts extracted from Wikipedia.

\begin{tabular}{|c|c|}
\hline Category & A snippet of the extracted article \\
\hline \multirow[b]{2}{*}{ Regions } & $\begin{array}{l}\text { Ang Caraga maoy usa sa mga rehiyon sa } \\
\text { Pilipinas nga makita sa pulo sa Mindanao. }\end{array}$ \\
\hline & $\begin{array}{l}\text { Ang Caraga ay isang rehiyon ng Pilipinas na } \\
\text { matatagpuan sa hilagang silangang bahagi ng } \\
\text { pulo ng Mindanao. }\end{array}$ \\
\hline \multirow{2}{*}{ Provinces } & $\begin{array}{l}\text { Ang Abra usa ka lalawigan sa Pilipinas sa } \\
\text { Administratibong Rehiyon sa Cordillera sa } \\
\text { Luzon. }\end{array}$ \\
\hline & $\begin{array}{l}\text { Ang Abra (Ilokano:Probinsiya ti Abra) ay } \\
\text { isang lalawigan ng Pilipinas na matagpuan sa } \\
\text { Cordillera Administrative Region sa Luzon. }\end{array}$ \\
\hline \multirow{2}{*}{$\begin{array}{c}\text { Tourism } \\
\text { Attractions }\end{array}$} & $\begin{array}{l}\text { Ang Malolos primera klaseng } \\
\text { nahimutang sa probensya sa } \\
\text { Pilipinas. }\end{array}$ \\
\hline & $\begin{array}{l}\text { Ang Lungsod ng Malolos ay isang unang } \\
\text { uring lungsod sa Pilipinas sa lalawigan ng } \\
\text { Bulacan. }\end{array}$ \\
\hline
\end{tabular}

Bible: In this source, we have observed that inconsistences in translation were mostly prevalent on nouns and verbs. We have seen inconsistences in the translation of names of people in the Bible from source to target which we think are very critical to address since the Bible has a lot of important biblical names. Shown in Table 4 are samples that were seen as inconsistent translations for most mentioned names in the source:

Table 4: Sample names extracted from the dataset with high frequency

\begin{tabular}{|c|c|c|c|}
\hline Names & $\begin{array}{l}\text { Possible } \\
\text { Translations }\end{array}$ & $\begin{array}{l}\text { Replaced } \\
\text { with }\end{array}$ & $\begin{array}{l}\text { \# of } \\
\text { Instances }\end{array}$ \\
\hline jehova & $\begin{array}{c}\text { jehova, } \\
\text { panginoon, } \\
\text { dios none }\end{array}$ & jehova & 1580 \\
\hline dios & $\begin{array}{c}\text { jehova, } \\
\text { panginoon, } \\
\text { dios none }\end{array}$ & dios & 622 \\
\hline israel & $\begin{array}{c}\text { katilingban, } \\
\text { israelita, } \\
\text { israelihanon, } \\
\text { none }\end{array}$ & israel & 665 \\
\hline moises & $\begin{array}{c}\text { moises, siya, } \\
\text { kaniya, none }\end{array}$ & moises & 651 \\
\hline aaron & aarong & aaron & 292 \\
\hline
\end{tabular}

It can be observed in Table 4, that both the words jehova and dios can be used to translate one from the other. There are instances in the dataset that the word jehova from the source is referred to as dios or panginoon. The none tag in the possible translation column is a case where in there is no equivalent translation of the word in the target language given a sentence pair. It can be noticed as well that most of the possible translations for the name moises are pronouns such as the words siya, kaniya.
Word translation was performed for most frequently occurring names that were inconsistent translated. We applied the copyable approach for word translation in names. Example, for the word dios it was found out that the most frequent translation of the word dios is also dios, therefore any instance that the word dios is found in the source language and is translated as panginoon or jehova; it will be replaced with the word dios. If none, the word dios will be inserted in the target language.

Table 5: Sample list of verbs and its possible translation

\begin{tabular}{|l|l|c|}
\hline Verbs & Possible Translations & $\begin{array}{l}\text { \# of } \\
\text { Instances }\end{array}$ \\
\hline ngadto & $\begin{array}{l}\text { pumaroon, bumaba, } \\
\text { pasubasob, none, } \\
\text { magsisiyaon, nagsibaba, } \\
\text { napasa, mula, paroon, } \\
\text { yumaon, papasasa }\end{array}$ & 541 \\
\hline sumala & $\begin{array}{l}\text { ayon, gaya ng, kung } \\
\text { paanong }\end{array}$ & 273 \\
\hline uban & kasalamuha, none & 332 \\
\hline
\end{tabular}

Aside from names, most frequently occurring verbs found in the dataset were examined. Table 5 shows 5 of the most frequently occurring verbs. Subword unit translation [3]. was performed in these words. Example, the word ngadto has 11 possible translations. After inspection it was found out that the most frequently used translation of the word ngadto is paroon. After knowing that the translation is paroon, all occurrences of the word ngadto in the source language was replaced with the word paroon in the target language.

Wikipedia: In this resource, we observed that majority of the articles has more number of sentences available in Filipino than in Cebuano. We manually examined each of the text files and exhaustively look up for sentence pairs that are translations of each other. We then observed that some of the sentence pairs for each category exhibits common features.

For regions, the word sequence maoy rehiyon sa Pilipinas in Cebuano, ay isang rehiyon sa Pilipinas in Filipino, is a region in the Philippines in English appeared 205 times or $13 \%$ of the sentence pairs under this category contains this word sequence. Examples of these sentences are:

1. Ang Lupot sa Cagayan maoy rehiyon sa Pilipinas.

2. Ang Administratibong Rehiyon sa Cordillera maoy rehiyon sa Pilipinas.

3. Ang Calabarzon maoy rehiyon sa Pilipinas nga gilangkuban sa mga musunod nga lalawigan: Cavite, Laguna, Batangas, Rizal at Quezon.

Other word sequence commonly found under this category is gilangkuban kini sa [count] ka lalawigan followed by a colon (:)

For cities, same as in provinces the word feature ceb::nabahin or fil::nahahati frequently occurs in the extracted texts. While provinces are composed of cities, cities on the other hand are composed of barangays.

\section{EXPERIMENT RESULTS}

In this section, results of training Cebuano to Filipino sentence pairs in a unidirectional Recurrent Neural Network (RNN) with and without corrections to the corpus are shown. Three experiments were performed: (1) the RNN model was fed with 
sentence pairs without subword translation, (2) the RNN model was fed with sentence pairs with subword translation, and (3) the RNN model was trained using the Wikipedia sentence pairs.

Table 6: Comparison of Translated Sentences with and without subword translation

\begin{tabular}{|c|c|c|c|c|c|}
\hline SP & Reference & $\begin{array}{c}\text { Result without Subword } \\
\text { Translation }\end{array}$ & $\begin{array}{l}\text { BLEU } \\
\text { Score }\end{array}$ & $\begin{array}{c}\text { Result with Subword } \\
\text { Translation }\end{array}$ & BLEU Score \\
\hline 1 & $\begin{array}{l}\text { at sinabi ng dios, sibula } \\
\text { n ang lupang damo, pan } \\
\text { anim na nagkakabinhi, } \\
\text { at punong kahoy na } \\
\text { namumunga ayon } \\
\text { sa kaniyang pagkakahoy } \\
\text {, na taglay ang kaniyan } \\
\text { g binhi sa ibabaw ng } \\
\text { lupa, at nagkagayon. }\end{array}$ & $\begin{array}{l}\text { at sinabi ng dios, purihin ang } 1 \\
\text { upa, at iniibig ang lupa, na tin } \\
\text { implahan ng kapahingahan, a } \\
\text { t tatalab sa kaniya } \\
\text { ang mga kahoy na iyon, na p } \\
\text { arang bunga ng kanilang binhi } \\
\text { : at magiging banal sa kaniya }\end{array}$ & 16.52 & $\begin{array}{l}\text { at sinabi ng dios, mapayapa } \\
\text { nawa ang lupain, at iginuhit sa } \\
\text { iyo, ng kasagutan at ng laryo, na } \\
\text { mga kahoy na itinutubo ng kahoy } \\
\text { sa lupain ; at siya'y naging } \\
\text { parang pakinabang sa ibabaw ng } \\
\text { lupa. }\end{array}$ & 18.97 \\
\hline 2 & $\begin{array}{l}\text { at ang lupa ay sinibulan } \\
\text { ng damo, pananim na } n \\
\text { agkakabinhi, ayon sa ka } \\
\text { niyang pagkapananim } \\
\text { at ng punongkahoy na } n \\
\text { amumunga, na taglay a } \\
\text { ng kaniyang binhi, ayon } \\
\text { sa kaniyang pagkakaho } \\
\boldsymbol{y} \text {, at nakita ng dios na m } \\
\text { abuti }\end{array}$ & $\begin{array}{l}\text { at ang lupain ay mapasuko, at } \\
\text { kumapal na parang binhi ng } \boldsymbol{p} \\
\text { akikiapid, na gaya ng kanilan } \\
\text { g ama : at ang mga } \\
\text { kahoy na cedro, ay ayon sa } \boldsymbol{k} \\
\text { anilang kapanganakan, at nak } \\
\text { ita ng dios na mabuti. }\end{array}$ & 24.08 & $\begin{array}{l}\text { at ang lupain ay mapasuko at nil } \\
\text { akad,, na mainam na harina, at } \\
\text { ang binhi ng pakikiapid, at ang } \boldsymbol{m} \\
\text { ga kahoy na } \\
\text { itinutubo ng kahoy na cedro, ay } \\
\text { magtataglay ng kanilang ulo at n } \\
\text { g dios na mabuti . }\end{array}$ & 15.05 \\
\hline 3 & $\begin{array}{l}\text { at nagkahapon at nagka } \\
\text { umaga ang ikatlong ara } \\
\mathrm{w} \text {. }\end{array}$ & $\begin{array}{l}\text { at may malakas na hiyawan sa } \\
\text { araw na yaon. }\end{array}$ & 5.52 & $\begin{array}{l}\text { at nagkahapon at nagkaumaga ang } \\
\text { ikatlong araw . }\end{array}$ & 100.00 \\
\hline
\end{tabular}

\subsection{Without Subword Translation (Bible)}

After splitting the corpus, training was performed. Logarithmic loss values generated during the training to measure the performance of the model on how far the source values are from the target indicated values were extracted. The ideal loss value is 0 . Training was stop at step $25000($ loss $=1.39)$ when loss was consistently below 2 starting step 21000 (loss =2). After the training, translation was evaluated using the test cases via the BLEU metric. Result of the evaluation is a BLEU score indicating that the higher the BLEU score the better the translation.

The model achieved a BLEU score of $\mathbf{2 0 . 0 1}$ for Cebuano to Filipino translation without the word and subword translation. This score indicates a somewhat understandable translation. Table 4 shows a sample translated sentences taken from the test set. The words that are strongly emphasized and italicized are the words not found in the translation.

Translations seem to have a much better BLEU score result on longer sentences compared to short sentences. This is because unigram correct translation is much higher on longer sentences. Although this is not true in all sentence pairs seen on the test set. An example would be the translation for this source sentence:

ug ang babaye mitubag sa bitin : makakaon kami sa bunga sa mga kahoy sa tanaman :

The correct translation should be:

at sinabing babae sa ahas, sa bunga ng mga punong kahoy sa halamanan ay makakakain kami

The machine translated it as:

at sinabi ng babae sa ahas, kami ay tumakas sa bunga ng $m$ ga punong kahoy,
This sentence pair got a high BLEU score of 58.07. In the translation table result shown in Table 6, it can be observed that in sentence pair 2 there is an insertion of the word cedro (a noun based on context) which is never seen in the source sentence. When the word cedro was searched in the whole training set, we found that the word cedro is a name of a tree which was always mentioned in the training set as kahoy na cedro. Looking at the sentence pair 2 in the test set, where punong kahoy was mentioned, the machine translated it as kahoy na cedro.

\subsection{With Subword Unit Translation (Bible)}

After performing subword translation as discussed in section 3.2, logarithmic training loss values generated during the training to measure the performance of the model on how far the source values are from the target indicated values were extracted. The ideal loss value is 0 . Training was stop at step $9000($ loss $=1.22)$ when loss was consistently below 2 .

The training, translation was evaluated using the test cases via the BLEU metric. The model achieved a slightly higher BLEU score of $\mathbf{2 2 . 8 7}$ for Cebuano to Tagalog translation with subword translation. Table 6 shows that the impact of the correction (Subword translation) is greatly seen on sentence pair number 3. A perfect translation of the reference sentence was outputted. On the other hand it did not performed well on sentence pair number 2 . The BLEU score got even lower.

\subsection{Wikipedia}

After splitting the corpus, training was performed. Just like the network parameter setup used in the Bible, we also used the same for Wikipedia. Logarithmic loss values generated during the training to measure the performance of the model on how far the source values are from the target indicated values were extracted. The ideal loss value is 0 . 
Training was stop when loss was consistently below 2 . After the training, translation was evaluated using the test cases via the BLEU metric. Result of the evaluation is a BLEU score indicating that the higher the BLEU score the better the translation.

The model achieved a BLEU score of $\mathbf{2 7 . 3 6}$ for Cebuano to Filipino translation. An increase of $\mathbf{4 . 4 6}$ was seen, slightly higher compared to that of the Bible dataset with subword unit translation. We observed that the model performed best in translating the first n-gram feature of the sentence such as the following sentences:

Table 7: Observed correct translation of the first word of the

\begin{tabular}{|c|c|}
\hline Reference & Translation \\
\hline $\begin{array}{l}\text { Ang simbahan ay mayama } \\
\text { n na pinagkalooban, na may } \\
\text { masarap na retablo, pulpito, } \\
\text { lectern at koro-kuwadra. }\end{array}$ & $\begin{array}{l}\text { Ang simbahan ay napinsala } \mathbf{n} \\
\text { a isang mapanganib na katibay } \\
\text { an kung nakukuha ng mga pwe } \\
\text { rsa ng kaaway,. }\end{array}$ \\
\hline $\begin{array}{l}\text { Ang mga espesyal na intere } \\
\text { s ay ang serye ng crypto- } \\
\text { collateral chapel na nagsasa } \\
\text { paw sa magkabilang panig } \\
\text { ng nave. }\end{array}$ & $\begin{array}{l}\text { Ang espesyal na konstruksyon } \\
\text { ay ginawa ng mga durog na } b \\
\text { ato na nakatuon sa magkabila } \\
\text { ng panig ng pasukan. }\end{array}$ \\
\hline
\end{tabular}

The model performed poorly on translation numbers such as dates, counts, and etc.

\section{Conclusion}

In this paper, a never before applied approach for language translation was applied for a Cebuano to Tagalog translator. A Recurrent Neural Network was used to implement the translator using OpenNMT framework. The performance of the translation was evaluated using the BLEU Score metric. Two different types of data were used in the experiments: religious (Bible) and data from Web (Wikipedia). To address inconsistencies of translation in the source dataset, a subword unit translation was performed. This correction results to an increased BLEU score of 22.87 from 20.01 .

Although, there was a slight increase in the translation performce, this still indicates a somehow understandable translation. For the Wikipedia dataset, the model performed better than that of the Bible with a slightly higher score of 4.46 . We observed that the model performed best in translating the first $n$-gram feature of the sentence and performed poorly on numeric features.

For future work, it is recommended to increase the number of training pairs to improve the translation performance. We also recommmend to leverage on the use of the identified topic segments or word sequences in Wikipedia to automatically extract parallel sentences.

\section{Acknowledgments}

We would like to thank De La Salle University and University of the Immaculate Conception for the financial support. Also, the Philippine Commission on Higher Education for the scholarship granted to one of the researchers.

\section{References}

[1] Christos Christodouloupoulos and Mark Steedman. 2015. A massively parallel corpus: the Bible in 100 languages. Language Resources and Evaluation. Volume 49, Issue 2, pp 375-395. https://link.springer.com/article/10.1007
[2] Durrani, H. Sajjad, H. Hoang, and P. Koehn. 2014. Integrating an Unsupervised Transliteration Model into Statistical Machine Translation. In Proceedings of the 14th Conference of the European Chapter of the Association for Computational Linguistics, EACL 2014, pages 148-153, Gothenburg, Sweden

[3] Dzmitry Bahdanau, KyungHyun Cho, and Yoshua Bengio. 2015. Neural Machine Translation by Jointly Learning to Align and Translate. In Proceedings of the International Conference on Learning Representations (ICLR). https://arxiv.org/pdf/1409.0473.pdf

[4] Ilya Sutskever, Oriol Vinyals, and Quoc V. Le. 2014. Sequence to Sequence Learning with Neural Networks. In Advances in Neural Information Processing Systems 27: Annual Conference on Neural Information Processing Systems 2014, pages 3104-3112, Montreal, Quebec, Canada

[5] Jasmine Ang, Mark Randell Chan., John Paolo Genato, Joyce Uy, and Joel Ilao. 2015. Development of a Filipino-to-English Bidirectional Statistical Machine Translation System that dynamically updates via user feedback. In Proceedings of the 12th International Workshop on Spoken Language Translation, Da Nang, Vietnam. http://workshop2015.iwslt.org/downloads/IWSLT_2015_RP_6.pdf

[6] Jacquiline G. Fat, (2007). T2CMT: Tagalog-to-Cebuano Machine Translation. Talamban, Cebu City: Department of Mathematics and Computer

Science. https://www.researchgate.net/publication/228711612_T2CMT_Taga log-to-Cebuano_Machine_Translation/

[7] Lazaro, A.N., Nathaniel Oco and Rachel Edita Roxas. 2017. Developing a Bidirectional Ilocano-English Translator for the Travel Domain: Using Domain Adaptation Techniques on Religious Parallel Corpora. Presented at the 11th International Conference of the Asian Association for Lexicography, Guangzhou, China.

[8] Nal Kalchbrenner and Phil Blunsom. 2013. Recurrent Continuous Translation Models. In Proceedings of the 2013 Conference on Empirical Methods in Natural Language Processing, Seattle. Association for Computational Linguistics. https://www.aclweb.org/anthology/D13-1176

[9] Nicco Noccon, Nathaniel Oco, Joel Ilao and Rachel Roxas. 2014 Philippine Component of the Network-based ASEAN Language Translation Public Service. In Proceedings of the 7th International Conference on Humanoid, Nanotechnology, Information Technology, Communication and Control, Environment, and Management, Puerto Princesa City, Philippines. https://ieeexplore.ieee.org/document/7016264

[10] Rico Sennrich, Barry Haddow and Alexandra Birch. 2016. Neural Machine Translation of Rare Words with Subword Units. Proceedings of the 54th Annual Meeting of the Association for Computational Linguistics, pages 1715-1725, Berlin, Germany, August 7-12, 2016. http://www.aclweb.org/anthology/P16-1162

[11] Sree Harsha Ramesh and Krishna Prasad Sankaranarayanan. 2018. Neural Machine Translation for Low Resource Languages using Bilingual Lexicon Induced from Comparable Corpora. Proceedings of NAACL-HLT 2018: Student Research Workshop, pages 112-119 New Orleans, Louisiana, June 2 - 4, 2018. http://aclweb.org/anthology/N18-4016 